\title{
MASS TRANSFER COEFFICIENTS FOR SUSPENDED PARTICLES IN AGITATED VESSELS AND BUBBLE COLUMNS*
}

\author{
YujI SANO, Nobutaka YAMAGUCHI aNd Toshiro ADACHI \\ Department of Chemical Engineering, Yamaguchi University, Ube
}

\begin{abstract}
Mass transfer coefficients of suspended particles were measured in agitated vessels and in bubble columns. Four sizes of agitated vessels (diameter: $9.5,17.5,20,40 \mathrm{~cm} \phi$ ) including both fully baffled and non-baffled conditions and two sizes of bubble columns (diameter: 10, $20 \mathrm{~cm} \phi$ ) were used. Particle sizes ranged from 60 to $1100 \mu \phi$ including both spherical beads (ion exchange resin) and granules (benzoic acid, $\mathrm{KMnO}_{4}$, and $\beta$-naphthol). We correlated the mass transfer coefficients using the surface factor as $\boldsymbol{S h}=\left[2+0.4\left(\varepsilon d_{p}^{4} / \nu^{3}\right)^{1 / 4} \cdot S c^{1 / 3}\right] \cdot \phi_{c}$

with a standard deviation of $30.8 \%$ for the Sherwood number. $S h[-]$ : Sherwood number, $\varepsilon\left[\mathrm{cm}^{2} / \mathbf{s e c}^{3}\right]$ : rate of energy dissipation, $\boldsymbol{d}_{p}[\mathrm{~cm}]:$ specific surface diameter, $\nu\left[\mathrm{cm}^{2} / \mathbf{s e c}\right]:$ kinematic viscosity, $S c[-]$ : Schmidt number and $\phi_{c}[-]$ : surface factor.
\end{abstract}

\section{Introduction}

Mass transfer for suspended particles in turbulent liquid flow is important in various chemical operations, such as slurry catalytic reaction, solid dissolution, crystallization and so on. Many reports on this problem have been published, especially about suspended particles in agitated vessels. Hixson and Baum $(1941)^{11)}$, Nagata and Yamaguchi $(1960)^{17)}$, Barker and Treybal $(1960)^{1)}$, Harriot $(1962)^{7)}$, and Brian et al. (1969) $)^{3)}$ are representative investigations for agitated vessels. But these investigations show a variety of results, and no reliable correlation for mass transfer coefficient has been found. Investigations of this problem in other equipment are rather few. Kawamura and Sasano ${ }^{14)}$ reported data for bubble columns and Harriot ${ }^{8)}$ those for pipe flow.

Variation between investigations may be partly due to the lack of knowledge of the relative flow field around particles moving freely in turbulent liquid in various kinds of equipment. Complex particle characters such as the shape factor, the specific surface, and the diameter distribution may be other causes of variation.

Approaches to predict the effect of flow behavior on mass transfer are classified into four groups. The first is mere dimensional analysis, in which the flow effect is presented in terms of the impeller Rey-

\footnotetext{
* Received on September 21, 1973 .

A part of this paper was presented at the 5 th Autumn

Meeting of The Soc. of Chem. Engrs., Japan, Osaka, Oct. 6, 19.71

干755 宇部市常盤台

山口大学工学部化学工学科 佐野雄二
}

nolds number based on the impeller diameter and tip velocity. But this parameter gives little information about the flow behaviour around particles. The second is the "slip velocity theory" proposed by Harriot $^{7}$. He started from the Ranz and Marshall equation $^{20)}$ for a single sphere in steady-state motion:

$$
S h=2+0.6 R e^{1 / 2} \cdot S c^{1 / 2}
$$

and tried to correlate the mass transfer coefficient of particles in agitated vessels with the coefficient of spherical particles moving at terminal velocity. However, he could only explain the qualitative analogy between them. Hughmark's correlation ${ }^{12)}$ of slip velocity would include some questions in his calculations of turbulence intensity effect, that must be accounted for in the mean relative velocity. The third is the non-steady state model, after Higbie's penetration theory. Otake et al. ${ }^{19)}$ tried to explain contact time using the population balance of eddies. The fourth is based on Kolmogoroff's theory of local isotropic turbulence.

It is the purpose of this report to find a correlation equation to predict the mass transfer coefficient of suspended particles in turbulent liquid flow not only for agitated vessels but also for other equipment, such as bubble columns.

\section{Reynolds Number Based on Kolmogoroff's Theory}

Turbulent phenomena are usually approached in the manner of statistical theory. However, Kolmogoroff developed a rather intuitive theory based on dimensional analysis. The details of the theory were described by Hinze ${ }^{10)}$. Kolmogoroff postulated that 


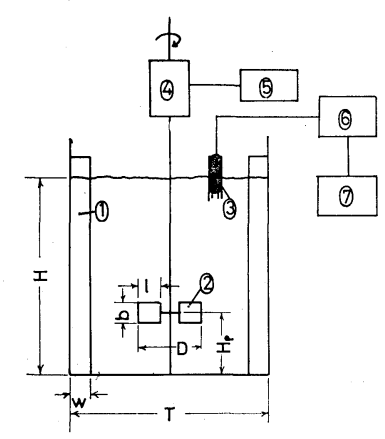

(1) baffle plate

(2) impeller

(3) Pt electrode

(4) torque pick up

(5) strain gauge meter

(6) conductivity meter

(7) quick response recorder

Fig. 1 Agitated vessel
Tabel 1 Dimensions of apparatus

\begin{tabular}{|c|c|c|c|c|c|}
\hline \multicolumn{6}{|l|}{ Agitated vessel } \\
\hline No. & $\mathrm{V}-1$ & $\mathrm{~V}-2$ & $\mathrm{~V}-3.1$ & $\mathrm{~V}-3.2$ & $\mathrm{~V}-4$ \\
\hline$T[\mathrm{~cm} \phi]$ & 17.5 & 9.5 & 20 & 20 & 40 \\
\hline$H[\mathrm{~cm}]$ & $\mathrm{T}$ & $\mathrm{T}$ & $\mathrm{T}$ & $\mathrm{T}$ & $\mathrm{T}$ \\
\hline Baffle (numb & ber & 4 & 4 & no baffle & 4 \\
\hline ?width & $0.1 \mathrm{~T}$ & $0.15 \mathrm{~T}$ & $0.15 \mathrm{~T}$ & - & $0.15 \mathrm{~T}$ \\
\hline Impeller & turbine & paddle & paddle & paddle & paddle \\
\hline$D[\mathrm{~cm} \phi]$ & $0.287 \mathrm{~T}$ & $0.33 \mathrm{~T}$ & $0.33 \mathrm{~T}$ & $0.33 \mathrm{~T}$ & $0.33 \mathrm{~T}$ \\
\hline$b[\mathrm{~cm}]$ & $0.2 \mathrm{D}$ & $0.2 \mathrm{D}$ & $0.2 \mathrm{D}$ & $0.2 \mathrm{D}$ & $0.2 \mathrm{D}$ \\
\hline$l[\mathrm{~cm}]$ & $0.3 \mathrm{D}$ & $0.5 \mathrm{D}$ & $0.5 \mathrm{D}$ & $0.5 \mathrm{D}$ & $0.5 \mathrm{D}$ \\
\hline$n_{p}[-]$ & 6 & 2 & 2 & 2 & 2 \\
\hline$H_{p}[-]$ & $0.33 \mathrm{~T}$ & $0.33 \mathrm{~T}$ & $0.33 \mathrm{~T}$ & $0.33 \mathrm{~T}$ & $0.33 \mathrm{~T}$ \\
\hline \multicolumn{6}{|l|}{ Bubble column } \\
\hline \multirow{3}{*}{$\begin{array}{l}\text { No. } \\
T[\mathrm{~cm} \phi] \\
H[\mathrm{~cm}]\end{array}$} & & \multicolumn{2}{|c|}{$T-1$} & \multicolumn{2}{|c|}{$\mathrm{T}-2$} \\
\hline & & \multirow{2}{*}{\multicolumn{2}{|c|}{10}} & \multicolumn{2}{|l|}{20} \\
\hline & & & & \\
\hline \multirow{2}{*}{$\begin{array}{l}\text { Gas } \\
\text { distributor }\end{array}$} & Dia. [mm $\phi]$ & \multicolumn{2}{|c|}{0.5} & & .5 \\
\hline & $\left\{\begin{array}{l}\text { Number } \\
\text { of holes }\end{array}\right.$ & \multicolumn{2}{|c|}{19} & \multicolumn{2}{|l|}{77} \\
\hline
\end{tabular}

the characters of eddies in the "equilibrium range", in which eddies were far smaller than the integral scale $L$ and could be considered isotropic, were dependent neither on the geometry of equipment nor on the method of flow energy supply. The eddies are then dependent on only two simple parameters, i.e., rate of energy dissipation per unit mass of fluid and kinematic viscosity. By taking length scale and velocity scale as the characteristic measures of these eddies, he deduced Eqs. (2) and (3) from dimensional reasoning:

$$
\begin{aligned}
& \eta=\left(\frac{\nu^{3}}{\varepsilon}\right)^{1 / 4} \\
& v=(\nu \varepsilon)^{1 / 4}
\end{aligned}
$$

where $\eta$ is the measure of eddy diameter, in which the maximum dissipation occurs. Kolmogoroff then postulated that the rms. of velocity difference $v_{d}$ between two points at the distance $d$ was given by

$$
\frac{v_{d}}{v}=f\left(\frac{d}{\eta}\right)=C \cdot\left(\frac{d}{\eta}\right)^{m}
$$

Kolmogoroff gave the following expression from dimensional reasoning:

$$
\begin{array}{cl}
\eta \ll d \ll L & v_{d} \cong(\varepsilon d)^{1 / 3} \\
d \ll \eta & v_{d} \cong(\varepsilon / \nu)^{1 / 2}
\end{array}
$$

Eq. (5) holds in the "inertial subrange" which may exist when the Reynolds number of the main flow is sufficiently large. Eq. (6) holds for the range of far smaller eddies than $\eta$. Shinnar and $\mathrm{Church}^{22)}$ used the Reynolds number $\left(v_{d} \cdot d / \nu\right)$ based on Eqs. (5) and (6) to correlate the diameter of dispersed droplets.

$$
\begin{array}{cl}
\eta \ll d \ll L & \frac{v_{d} \cdot d}{\nu}=C_{1}\left(\frac{\varepsilon d^{4}}{\nu^{3}}\right)^{1 / 3} \\
d \ll \eta & \frac{v_{d} \cdot d}{\nu}=C_{2}\left(\frac{\varepsilon d^{4}}{\nu^{3}}\right)^{1 / 2}
\end{array}
$$

Middleman $^{16)}$ gave the correlation equations for mass transfer coefficient of particles by combining Eq. (7) or (8) with impeller power input. Oyama and Endo $^{18)}$ gave the same kind of correlation equation in a different manner. Brian et al. ${ }^{3)}$ used the parameter of $\left(\varepsilon d^{4} / \nu^{3}\right)$ and first showed the correlation of $\left(S h / S c^{1 / 3}\right)$ vs. $\left(\varepsilon d^{4} / \nu^{3}\right)$ for agitated vessels. Kawamura and Sasano ${ }^{14)}$ gave the correlation of $\left(S h / S c^{1 / 3}\right)$ vs. $\left(\varepsilon^{6 / 12} d^{5 / 3} / \nu^{15 / 12}\right)$ for bubble columns, based on the assumption of $v_{d} \propto \varepsilon^{5 / 12}$ for the range of $d \cong \eta$. Levins and Grastonburg ${ }^{15)}$ criticized these correlation methods, showing the effect of density difference and impeller diameter. They also questioned the validity of Eq. (7) for agitated vessels, because $R e_{\lambda}$ is much smaller in the usual operating conditions. But generally the Reynolds number based on Kolmogoroff's theory for suspended particles of diameter $d$ can be expressed as follows:

$$
\frac{v_{d} \cdot d}{\nu}=\frac{C(d / \eta)^{m} \cdot v \cdot d}{\nu}=C\left(\frac{\varepsilon d^{4}}{\nu^{3}}\right)^{(\mathrm{m}+1) / 4}
$$

and can be represented in term of $\left(\varepsilon d^{4} / \nu^{3}\right)$ regardless of particle diameter range as long as particle diameter is less than that of the largest eddies in the equilibrium range. For example, if $m=1 / 3$ or $m=1$, Eq. (7) or (8) is obtained and if $m=2 / 3$, Kawamura and Sasano's parameter is reached. The exponent of $\left(\varepsilon d^{4} / \nu^{3}\right)$ in the correlation of $\left(S h / S c^{1 / 3}\right)$ vs. $\left(\varepsilon d^{4} / \nu^{3}\right)$ shown by Brian et al., increased with increasing values of $\left(\varepsilon d^{4} / \nu^{3}\right)$. But, when considering Eq. (1), Eq. (7) for larger range of $\left(\varepsilon d^{4} / \nu^{3}\right)$ gives a smaller exponent value for $\left(\varepsilon d^{4} / \nu^{3}\right)$ than that obtained from Eq. (8) for smaller range of $\left(\varepsilon d^{4} / \nu^{3}\right)$. A possible explanation for this question is that the diffusion term for a sphere, i.e. the value of 2 in Eq. (1), must be considered in the correlation:

$$
S h=2+C \cdot\left(\varepsilon d^{4} / \nu^{3}\right)^{\alpha} \cdot S c^{\beta}
$$

This correlation does not depend on the geometry of the equipment nor on the method of flow energy imput.

\section{Experimental Apparatus and Procedure}

Agitated vessels and bubble columns were used as the experimental apparatus. Figure 1 and Table 1 show the dimensions of the agitated vessels used. 
All vessels were filled with liquid to a depth equal to their diameters. In order to know the scale effect, four vessels of different diameter $(9.5,17.5,20$, and $40 \mathrm{~cm} \phi$ ) were used. Three vessels of diameter 9.5, 20 , and $40 \mathrm{~cm} \phi$ were equipped with four symmetrically located baffles whose widths were $15 \%$ of the vessel diameter. These baffles satisfy the fully baffled condition. The impellers of these three vessels were flat, 2-bladed paddles with diameters of $D / 3$. In the $17.5 \mathrm{~cm} \phi$ vessel, the width of four baffles was $10 \%$ of the vessel diameter, which gave a weaker baffle effect. In this vessel, the impeller was a sixbladed turbine of $D / 3$ dia. In the $20 \mathrm{~cm} \phi$ vessel, the non-baffled condition was also examined. All vessels were placed in a constant-temperature bath of $20^{\circ} \mathrm{C}$.

Bubble columns are shown in Fig. 2 and Table 1. Column diameters of 10 and $20 \mathrm{~cm} \phi$ were used. The bubble distributor for $10 \mathrm{~cm} \phi$ column was a perforated plate with 19 holes of $0.5 \mathrm{~mm} \phi$ which were arranged in a triangular manner with $20 \mathrm{~mm}$ pitch. In the $20 \mathrm{~cm} \phi$ column, the distributor had 77 holes with $0.5 \mathrm{~mm} \phi$ arranged in the same manner with $20 \mathrm{~mm}$ pitch. Columns were made of acrylic resin and were equipped with a temperature control jacket kept at $20^{\circ} \mathrm{C}$.

In order to find the effect of particle shape, both spherical and granular particles were used. Spherical particles were ion exchange beads of Dowex $50 \mathrm{~W} \times 8$, a moderately cross-linked strong acid resin. Resin beads were screened with water into narrow rangediameter fractions. These beads were prepared to Na-type and were kept in the equilibrium state of swelling with deionized water. Diameter and density of the beads were measured in this state.

A known amount of resin beads was put into a $2 \times 10^{-3} \mathrm{~N} / l \mathrm{HCl}$ solution prepared with deionized water in the apparatus and the conductivity change with time was measured with a Pt electrode and a quick-response recorder. The relation of conductivity and $\mathrm{H}^{+}$ion concentration in coexistence with $\mathrm{Na}^{+}$ion were measured beforehand, by measuring the conductivity of $\mathrm{HCl}$ solution neutralized partially with a known amount of $\mathrm{NaOH}$ solution. The concentration of $\mathrm{HCl}$ solution was made low enough so that the external resistance of mass transfer was rate-controlling, which was checked by Helfelich's equation $^{9)}$ using the internal diffusion coefficient value of the resin as given by Turner et $a .^{24)}$. The diffusion coefficient of $\mathrm{H}^{+}$and $\mathrm{Na}^{+}$were calculated from the data of ion mobility.

Granular particles were obtained by crushing of molten benzoic acid, $\mathrm{KMnO}_{4}$ and $\beta$-naphthol. These particles were screened into a fraction of narrow range diameter and then the specific surface area was measured by the permeability method, using Ergan's

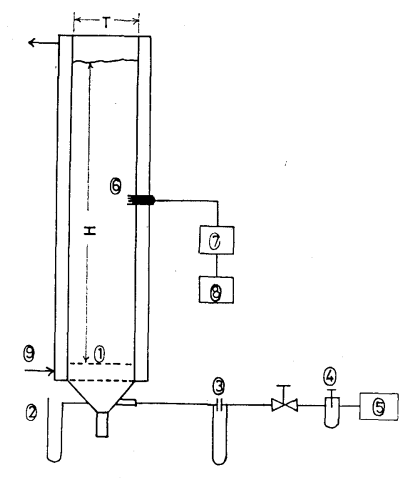

(1) perforated plate

(2) manometer

(3) orifice

(4) reduced pressure valve

(5) compressor

(6) Pt electrode

(7) conductivity meter

(8) quick response recorder

(9) jacket water

Fig. 2 Bubble column

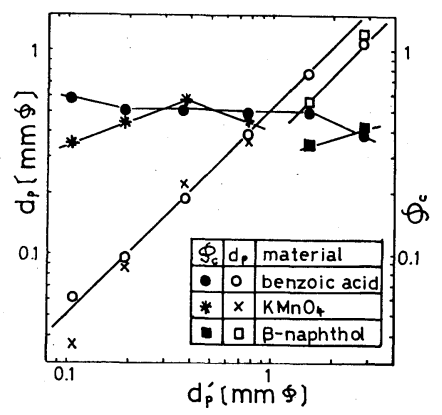

Fig. 3 Specific surface dia. and Carman's surface factor

equation ${ }^{5)}$. Specific surface diameter and Carman's surface factor based on screen dia. $d_{p}^{\prime}$ were obtained from Eqs. (11) and (12).

$$
\begin{aligned}
& d_{p}=6 /\left(\rho_{p} \cdot S_{w}\right) \\
& \phi_{c}=6 /\left(\rho_{p} \cdot S_{w} \cdot d_{p}^{\prime}\right)
\end{aligned}
$$

Figure 3 shows specific surface diameter and Carman's surface factor vs. screen diameter.

Mass transfer coefficients of granular particles were obtained from dissolution. A known amount of granular particles was put into deionized water in the apparatus and concentration changes over time were measured. Concentrations were measured by means of a Pt electrode with a quick-response recorder for benzoic acid and $\mathrm{KMnO}_{4}$ and by ultraviolet spectrophotometry for $\beta$-naphthol solution. Samples for $\beta$-naphthol solution were taken from the apparatus at appropriate time intervals.

The properties of materials used are shown in Table 2.

\section{Calculation of Mass Transfer Coefficient}

Mass transfer coefficients were calculated in the following manner.

Ion exchange resin

The rate of ion exchange is

$$
N=k a\left(y_{b}-y_{i}\right) C_{0}=-\frac{d y_{b}}{d t} \cdot C_{0} V
$$

For spherical particles

$$
a=6 W / \rho_{p} d_{p}
$$

From Turner's results ${ }^{23)}$, which were based on the 


\begin{tabular}{|c|c|c|c|c|c|c|c|c|c|c|}
\hline \multirow[b]{2}{*}{ Solid } & \multirow[b]{2}{*}{$\begin{array}{c}d_{p}^{\prime} \\
{[\mu \phi]}\end{array}$} & \multicolumn{7}{|c|}{ Table 2 Properties of solid particle $\left(20^{\circ} \mathrm{C}\right)$} & \multirow[b]{2}{*}{$\frac{n[\text { r.p.m. }]}{U_{g}[\mathrm{~cm} / \mathrm{sec}]}$} & \multirow[b]{2}{*}{$\begin{array}{l}\text { wt. } \% \\
\text { of } \\
\text { solid }\end{array}$} \\
\hline & & $\begin{array}{l}d_{p} \\
{[\mu \phi]}\end{array}$ & {$[-]$} & $\begin{array}{c}C_{s} \\
{[\mathrm{~g} / \mathrm{cc}]}\end{array}$ & $\begin{array}{c}\rho_{p} \\
{[\mathrm{~g} / \mathrm{cc}]}\end{array}$ & $\begin{array}{c}D \\
{\left[\mathrm{~cm}^{2} / \mathrm{sec}\right]}\end{array}$ & $\begin{array}{c}S c \\
{[-]}\end{array}$ & Apparatus & & \\
\hline $\begin{array}{l}\text { Ion ex. resin } \\
\text { (Na type) }\end{array}$ & $\dot{-}$ & $\begin{array}{l}60 \\
\sim 833\end{array}$ & 1 & - & 1.40 & $\begin{array}{c}D_{\mathrm{H}^{+}}=8.5 \times 10^{-5} \\
D_{\mathrm{Na}}{ }^{+}=1.19 \times 10^{-5}\end{array}$ & 217 & $\begin{array}{l}\mathrm{V}-2, \mathrm{~V}-3,1 \\
\mathrm{~V}-3,2, \mathrm{~V}-4 \\
\mathrm{~T}-1, \mathrm{~T}-2\end{array}$ & $\begin{array}{l}240 \sim 1600 \\
0.5 \sim 17\end{array}$ & $\begin{array}{l}0.05 \\
\sim 0.1\end{array}$ \\
\hline Benzoic acid & $\begin{array}{l}107 \\
\sim 2850\end{array}$ & $\begin{array}{l}66 \\
\sim 1080\end{array}$ & $\begin{array}{l}0.49 \\
\sim 0.58\end{array}$ & $2.9 \times 10^{-3}$ & 1.31 & $0.78 \times 10^{-5}$ & 1280 & $\mathrm{~V}-1, \mathrm{~T}-1$ & $\begin{array}{l}240 \sim 1600 \\
0.5 \sim 17.5\end{array}$ & 0.06 \\
\hline $\mathrm{KMnO}_{4}$ & $\begin{array}{l}107 \\
\sim 780\end{array}$ & $\begin{array}{l}79 \\
\sim 333\end{array}$ & $\begin{array}{l}0.44 \\
\sim 0.57\end{array}$ & $6.25 \times 10^{-2}$ & 2.70 & $1.59 \times 10^{-5}$ & 628 & $\mathrm{~V}-1, \mathrm{~T}-1$ & $\begin{array}{l}400 \sim 1600 \\
0.5 \sim 17.3\end{array}$ & 0.15 \\
\hline$\beta$-naphthol & $\begin{array}{l}1530 \\
\sim 2850\end{array}$ & $\begin{array}{l}520 \\
\sim 1140\end{array}$ & $\begin{array}{l}0.34 \\
\sim 0.40\end{array}$ & $0.60 \times 10^{-3}$ & 1.22 & $0.71 \times 10^{-5}$ & 1410 & $\mathrm{~V}-3,1, \mathrm{~T}-1$ & $\begin{array}{c}700 \sim 1200 \\
14.0\end{array}$ & $6 \times 10^{-3}$ \\
\hline
\end{tabular}

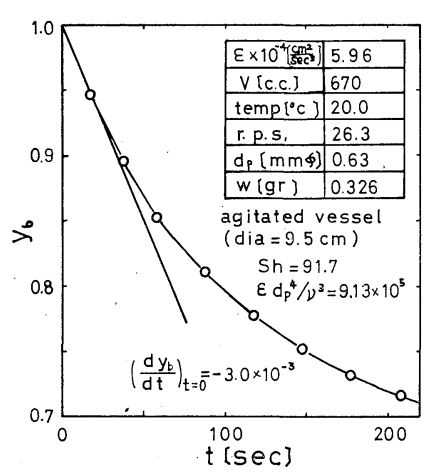

Fig. 4 Sample data of ion exchange resin

film theory with Nernst-Plank equation,

$$
k=\frac{2}{\left(1+\alpha^{\prime} y_{i}\right)+\sqrt{\left(1+\alpha^{\prime} y_{i}\right)\left(1+\alpha^{\prime} y_{b}\right)}} \cdot \frac{D_{H}}{\delta}
$$

where

$$
\alpha^{\prime}=\frac{D_{\mathrm{H}^{+}}}{D_{\mathrm{Na}}{ }^{+}}-1
$$

In the early period of ion exchange, we can put $y_{b} \cong 1$ and $y_{i} \cong 0$

$$
k \risingdotseq-\frac{V}{a} \frac{d \ln y_{b}}{d t} \doteqdot-\frac{V \cdot \rho_{p} d_{p}}{6 W}\left(\frac{d y_{b}}{d t}\right)_{t=0}
$$

Time vs. $y_{b}$, which was obtained from $\mathrm{H}^{+}$ion concentration, was plotted. Graphical differentiation of this plot gave the value of $d y_{b} / d t$ at $t=0 . \quad k$ was calculated from Eq. (16). The error of this method on the value of $k$ is $10 \%$ or less. Typical data for calculation of $k$ are shown in Fig. 4. $y_{i}$ was obtained from equilibrium data and was negligibly small in the early period of ion exchange. Diffusivity for this $k$ was then $2 D_{\mathrm{H}^{+}} /\left(1+\sqrt{1+\alpha^{\prime}}\right)$ from Eq. (15), taking $y_{b} \cong 1$ and $y_{i} \cong 0$.

\section{Granular particle}

The rate of dissolution is

$$
N=k a\left(C_{s}-C\right)=V \frac{d C}{d t} .
$$

Surface area is calculated from

$$
a=W S_{w}=S_{w_{0}} \cdot W_{0} \cdot\left(\frac{W}{W_{0}}\right)^{2 / 3}
$$

In Eq. (18) we assumed that the mass of undissolved particles was proportional to the cubic value of particle diameter at any given time, i.e. $W \propto d_{p}^{3}$.

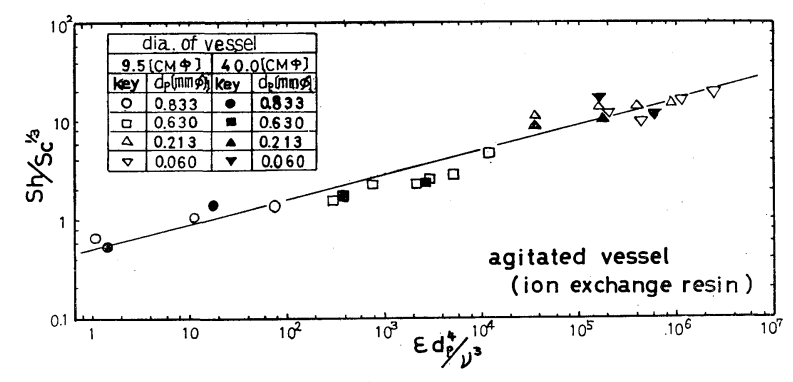

Fig. $5 S h / S c^{1 / 3}$ vs. $\varepsilon d_{p}^{4} / \nu^{3}$ for scale effects of agitated vessel

Then

$$
d_{p}=d_{p_{0}}\left(\frac{W}{W_{0}}\right)^{1 / 3}
$$

The mass of undissolved particles was calculated from mass balance.

$$
W=W_{0}-V \cdot C
$$

Mass transfer coefficient is expressed in the following equation, using Eqs. (17), (18) and (19).

$$
k=\frac{-V}{S_{w_{0}} \cdot W_{0} \cdot\left(W / W_{0}\right)^{2 / 3}} \cdot \frac{d}{d t} \ln \left(C_{s}-C\right)
$$

From the experimental data, $\log \left(C_{s}-C\right)$ vs. $t$ was plotted and $d \ln \left(C_{s}-C\right) / d t$ was obtained by graphical differentiation in the initial period of dissolution.

The energy supplied to liquid flow was calculated from Eq. (22) for agitated vessels and Eq. (23) for bubble columns.

$$
\begin{aligned}
& \varepsilon=\frac{P \cdot g_{c}}{V \rho_{l}}=\frac{N_{p} \cdot l^{5} \cdot n^{3}}{V} \\
& \varepsilon=\frac{g_{c} \Delta P \cdot Q}{L_{0} A \rho_{l}}=u_{g} \cdot g
\end{aligned}
$$

The power consumption of impeller $P$ was measured in most of the runs by a strain gauge torque meter. The power number of ' $N_{p}=5.0$ from Bate's results ${ }^{2}$ was used for the $17.5 \mathrm{~cm}$ vessel data.

\section{Results and Discussion}

Mass transfer coefficients were all converted to the non-dimensional form of the Sherwood number. It was assumed that the exponent of $S c$ was $1 / 3$ from the results of many investigations of mass transfer. A portion of the data are shown in Figs. 5 7, plotted in the manner of $S h / S c^{1 / 3}$ vs. $\left(\varepsilon d_{p}^{4} / \nu^{3}\right)$, and all data are summarized in Fig. 8. 


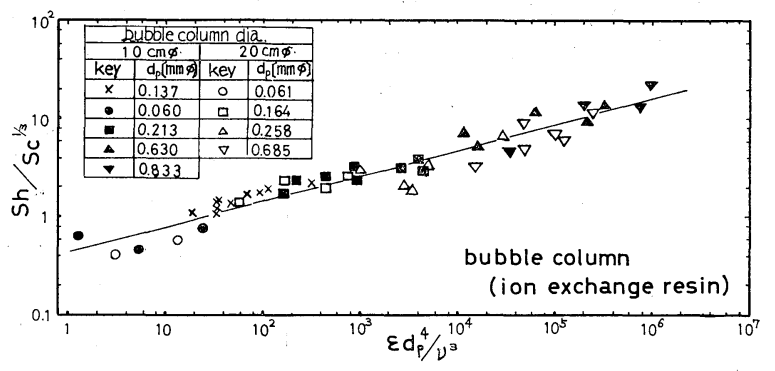

Fig. $6 S h / S c^{1 / 3}$ vs. $\varepsilon d_{p}^{4} / \nu^{3}$ for bubble column

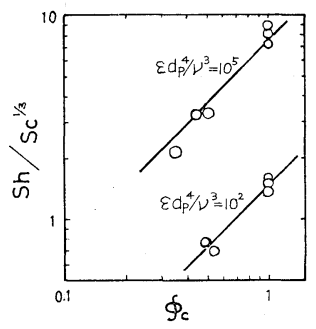

Fig. 8 Effect of $\phi_{c}$

\section{Effect of the geometry of agitated vessels}

Figure 5 shows the correlation for geometrically similar agitated vessels (dia. 9.5 and $40 \mathrm{~cm} \phi$ ) with paddle impeller and with four baffles of $0.15 \mathrm{D}$ width. These correlations show almost the same results, and therefore no effect of vessel diameter is observed in the correlations. The effect of baffle plates for the $20 \mathrm{~cm}$ diameter vessel can be seen in Fig. 9 . $S h / S c^{1 / 3}$ for the nonbaffled condition shows slightly larger values than that for fully baffled conditions in the whole range of $\left(\varepsilon d_{p}^{4} / \nu^{3}\right)$. But the difference between them is negligible and therefore effect of baffle plate can be represented in the term of $\left(\varepsilon d_{p}^{4} / \nu^{3}\right)$.

Cutter $^{6)}$ showed that the local rate of turbulent energy dissipation varied by 270 -fold throughout a agitated vessel. This raises questions for the simple correlation of $S h / S c^{1 / 3}$ vs. $\left(\varepsilon d_{p}^{4} / \nu^{3}\right)$. We ${ }^{21)}$ measured the local mass transfer coefficient and obtained a 4-fold variation in the agitated vessels. But the volume average values of local mass transfer coefficients were consistent with the results reported here.

\section{Effects of the geometry of the bubble column}

Figure 6 shows the correlation for bubble columns. The results of two columns with 10 and $20 \mathrm{~cm} \phi$ diameter were in close agreement. The effect of column diameter and the shape of gas distributor can be represented by $\left(\varepsilon d_{p}^{4} / \nu^{3}\right)$.

\section{Effects of the method of flow energy supply}

Agitated vessels and bubble columns supply energy to liquid flow in a different manner, namely, the former by impeller revolution and the latter by upward motion of bubbles. Comparisons of correlations for each, as shown in Figs. 5 and 7, show that they were almost coincident. These results show that the mass transfer coefficient of suspended particles in tur-

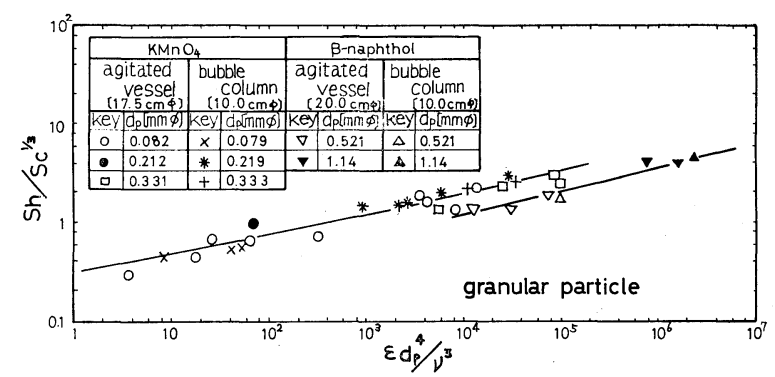

Fig. $7 \boldsymbol{S h} / \boldsymbol{S c}^{1 / 3}$ vs. $\boldsymbol{\varepsilon} d_{p} p^{4} / \nu^{3}$ for $\mathrm{KMnO}_{4}$

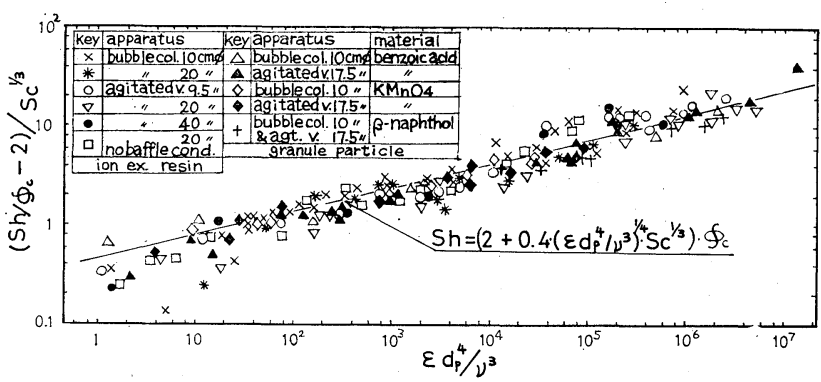

Fig. 9 Correlation of $\left(S h / \phi_{c}-2\right) / S c^{1 / 3}$ vs. $\varepsilon d_{p} p^{4} / \nu^{3}$

bulent liquid is well correlated by the parameter of $\left(\varepsilon d_{p}^{4} / \nu^{3}\right)$ regardless of equipment geometry or the method of energy supply.

\section{Effects of granular shape}

The effects of particle shape were examined by measuring the dissolution rate of granular particles of benzoic acid, $\mathrm{KMnO}_{4}$ and $\beta$-naphthol, whose shape factor was given in Fig. 3 .

The correlation curves for $\mathrm{KMnO}_{4}$ and for $\beta$ naphthol are shown in Fig. 7.

The $S h / S c^{1 / 3}$ of $\beta$-naphthol showed smaller values than that of $\mathrm{KMnO}_{4}$. The correlations for benzoic acid particles are summarized in Fig. 9. The difference between them and the difference between spherical and granular particles demonstrate the effect of the particle shape factor. The values of $S h / S c^{1 / 3}$ at $\left(\varepsilon d_{p}^{4} / \nu^{3}\right)=10^{5}$ and $10^{2}$ were evaluated from these figures. Then these values were plotted with Carman's surface factor, as shown in Fig. 8. The slope in Fig. 8 is almost equal to 1.0 , neglecting the tendency of the larger value at $\left(\varepsilon d_{p}^{4} / \nu^{3}\right)=10^{5}$. The mass transfer coefficient for granular particles divided by the surface factor $k / \phi_{c}$ was almost equal to the mass transfer coefficient for a sphere. This means that the surface area for mass transfer of granular particles is approximately equivalent to that calculated as spheres using the screen diameter.

\section{Correlation equation}

As suggested before, Eq. (10) is preferable for correlation, in which the effect of surface factor might be accounted in the value of $S h$. The correlation of $\left[\left(S h / \phi_{c}\right)-2\right] / S c^{1 / 3}$ vs. $\left(\varepsilon d_{p}^{4} / \nu^{3}\right)$ is shown for all data in Fig. 9.

The correlating equation is 


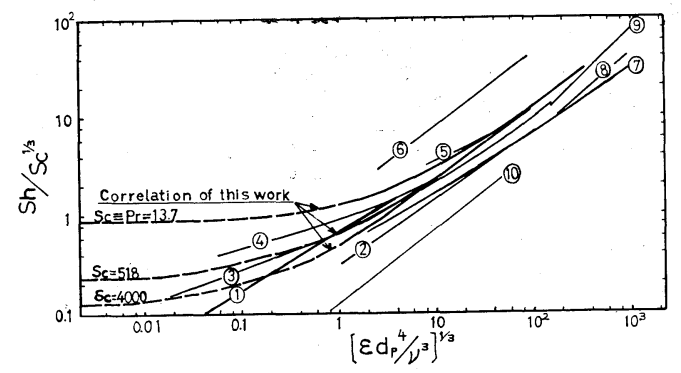

(1) Kawamura \& Sasano ${ }^{14}, S c=712 \sim 1020$

(2) Ishii \& Fujita ${ }^{13)}, S c=1000$

(3) Harriot, $S c>3600$

(4) Harriot, $S c=518$

(5) $\mathrm{Brian}^{3)}, \operatorname{Pr}=13.8$

(6) Bieber \& Gaden, $S c=1124$

(7) Harriot, $S c=1000-11000$

(8) Barker \& Treybal, $S c=735-1328$

(9) Wilhelm et al., $S c=950$

(10) Caldcrbank ${ }^{4}$

Curves of (3)-(9) were recited from Brian et al. ${ }^{31}$

Fig. 10 Comparison with other investigations

$$
S h=\left[2+0.4\left(\varepsilon d_{p}^{4} / \nu^{3}\right)^{1 / 4} S c^{1 / 3}\right] \cdot \phi_{c}
$$

The experimental range of various parameters is given in Table 2. The standard deviation for $S h$ is $30.8 \%$. The remaining problem discussed in many reports, is the effect of density difference between particles and liquid. The maximum density difference in this report was $1.70 \mathrm{~g} / \mathrm{cc}$ of $\mathrm{KMnO}$, and no effects of this factor were found in the correlations in our experimental range for completely suspended particles.

\section{Comparison of results with other investigations}

Figure 10 shows the comparison of the correlation curve with other experimental data in terms of $S h / S c^{1 / 3}$ vs. $\left(\varepsilon d_{p}^{4} / \nu^{3}\right)$ as shown by Brian et al. ${ }^{3}$. The following three correlations were added to Brian's comparison. Calderbank and Moo Young') presented the following correlations for fixed submerged bodies in turbulent liquid.

$$
k \cdot S c^{1 / 3}=0.13\left[\frac{(P / V) \mu}{\rho_{l}^{2}}\right]^{1 / 4}
$$

Kawamura and Sasano ${ }^{14)}$ reported the mass transfer coefficient for dissolution of fine powder (benzoic acid, $\mathrm{CaCO}_{3}, \mathrm{BaCO}_{3}$, and $\mathrm{PbI}_{2}$ ) suspended in a bubble column of $14 \mathrm{~cm} \phi$ diameter and gave the following correlation.

$$
S h=0.72\left[\frac{(P / V)^{5 / 12} \rho_{l}^{5 / 6} \cdot d_{p}^{\prime 5 / 3}}{\mu^{5 / 4}}\right]^{1 / 2} S c^{1 / 3}
$$

Ishii and Fujita ${ }^{13)}$ gave the following correlation for dissolution of $\mathrm{K}_{2} \mathrm{SO}_{4}$ in agitated vessels.

$$
S h=1.00 \times 10^{-1}\left[\frac{N_{p}^{1 / 3} \cdot n \cdot l^{5 / 3} \cdot d_{p}^{\prime 4 / 3}}{T \nu}\right]^{0.690} S c^{0.5}
$$

Eqs. (25), (26) and (27) can be expressed as follows.

$$
S h=0.13\left(\varepsilon d_{p}^{4} / \nu^{3}\right)^{1 / 4} S c^{1 / 3}
$$

$$
\begin{aligned}
& S h=0.72\left(\varepsilon d_{p}^{4} / \nu^{3}\right)^{0.208} S c^{1 / 3} \\
& S h=0.095\left(\varepsilon d_{p}^{4} / \nu^{3}\right)^{0.23} \cdot S c^{0.5}
\end{aligned}
$$

These equations are plotted in Fig. 10, where Eq. (30) shown as $S c=1000$.

The correlation of this report, Eq. (24), as shown in Fig. 10 has values of $S c=13.7,518$, and 4000, which are to be compared with curves reported by Brian et al. ${ }^{3)}$. Eq. (24) coincides fairly well with Brian's data and explains especially the branching tendency of the correlation due to $S c$. They suggested that the exponent of $S c$ would be better taken as a lower value than $1 / 3$. But the branching of the correlation by Brian et al. ${ }^{3)}$ may be due to the lack of the diffusion term, i.e. the value 2 in Eq. (1). Eq. (28) by Calderbank ${ }^{4}$ for fixed bodies shows the lowest value. Kawamura and Sasano's data ${ }^{14}$ are almost consistent with Brian's replotted data of Harriot ${ }^{7)}$ and data in this report in the range of $\left(\varepsilon d_{p}^{4} / \nu^{3}\right)=20 \sim$ 0.3 , but give lower values in the lower range of $\left(\varepsilon d_{p}^{4} / \nu^{3}\right)$. Eq. (29) by Ishii and Fujita ${ }^{13)}$ for granular particles gives lower values but almost agrees with Harriot's data ${ }^{7)}$ of granular particles. These data would be expected to come nearer to ours if the effect of shape factor had been taken into account.

\section{Conclusion}

The following correlation equation for mass transfer coefficients of suspended particles in turbulent liquid was obtained covering the range of $\left(\varepsilon d_{p}^{4} / \nu^{3}\right)$ from 1 to $10^{7}$ with a standard deviation of $30.8 \%$ for $S h$.

$$
S h=\left[2+0.4\left(\varepsilon d_{p}^{4} / \nu^{3}\right)^{1 / 4} S c^{1 / 3}\right] \cdot \phi_{c}
$$

The effects of equipment geometry and the method of flow energy supply were found to be neglibible for both agitated vessels and bubble columns. The effects of particle shape were accounted for in terms of Carman's shape factor. Solids used in the experiment were ion exchange beads for the spherical particles and benzoic acid, $\mathrm{KMnO}_{4}$, and $\beta$-Naphthol for the granular particles. The diameters of the particles ranged from 60 to $1100 \mu \phi$.

\section{Nomenclature}

$\left[\mathrm{cm}^{2}\right]$

$\left[\mathrm{mol} / \mathrm{cm}^{3}\right]$ $\left[\mathrm{mol} / \mathrm{cm}^{3}\right]$

[cm]

[cm]

[cm]

$\left[\mathrm{cm}^{2} / \mathrm{sec}\right]$

$=$ acceleration of gravity $\quad\left[\mathrm{cm} / \mathrm{sec}^{2}\right]$

$=$ gravitational conversion constant $\left[\mathrm{gr} \cdot \mathrm{cm} / \mathrm{Gr} \cdot \mathrm{sec}^{2}\right]$

$=$ mass transfer coefficient $\quad[\mathrm{cm} / \mathrm{sec}]$

$=$ integral scale of eddy $\quad[\mathrm{cm}]$

$=$ diameter of impeller [cm]

$=V \mid A$ for bubble column $\quad[\mathrm{cm}]$

$=$ mass transfer rate $\quad[\mathrm{mol} / \mathrm{sec}]$ 


\begin{tabular}{|c|c|c|}
\hline$N_{p}$ & $=$ power number $p g_{c} / p_{e} n^{3} l^{5}$ & {$[-]$} \\
\hline$n$ & $=$ rps. for impeller & {$[\mathrm{rad} / \mathrm{sec}]$} \\
\hline$P$ & $=$ power consumption of impeller & {$[\mathrm{Gr} \cdot \mathrm{cm} / \mathrm{sec}]$} \\
\hline$\Delta P$ & $=$ gas pressure drop in bubble column & {$\left[\mathrm{Gr} / \mathrm{cm}^{2}\right]$} \\
\hline$Q$ & $\begin{array}{l}=\text { volume velocity of gas in bubble } \\
\text { column }\end{array}$ & {$\left[\mathrm{cm}^{3} / \mathrm{sec}\right]$} \\
\hline $\operatorname{Re}$ & $=$ Reynolds number $v_{d} \cdot d / \nu$ & [-] \\
\hline $\operatorname{Re}_{\lambda}$ & $=$ Reynolds number based on $\lambda, v \lambda / \nu$ & {$[-]$} \\
\hline$S c$ & $=$ Schmidt number, $\nu / D$ & {$[-]$} \\
\hline$S h$ & $=$ Sherwood number, $k d_{p} / D$ & {$[-]$} \\
\hline$u_{g}$ & $\begin{array}{l}=\text { superficial velocity of gas for } \\
\text { bubble column }\end{array}$ & {$[\mathrm{cm} / \mathrm{sec}]$} \\
\hline$v_{d}$ & $\begin{array}{l}=\text { velocity difference between two points } \\
\text { at a distance } d\end{array}$ & {$[\mathrm{~cm} / \mathrm{sec}]$} \\
\hline$S w$ & $=$ specific surface area & {$\left[\mathrm{cm}^{2} / \mathrm{g}\right]$} \\
\hline$T$ & $=$ diameter of apparatus & [cm] \\
\hline$t$ & $=$ time & [sec] \\
\hline$V$ & $=$ volume of liquid & {$\left[\mathrm{cm}^{3}\right]$} \\
\hline$W$ & $=$ mass of particles & [g] \\
\hline$y_{b}$ & $=$ mol fractions of $\mathrm{H}^{+}$ion in bulk flow & {$[-]$} \\
\hline$y_{i}$ & $=$ mol fractions of $\mathrm{H}^{+}$at the interface & {$[-]$} \\
\hline$\delta$ & $=$ thickness of boundary film & [cm] \\
\hline$\varepsilon$ & $\begin{array}{l}=\text { rate of flow energy supply per } \\
\text { unit mass of liquid }\end{array}$ & {$\left[\mathrm{cm}^{2} / \mathrm{sec}^{3}\right]$} \\
\hline$\eta$ & $=$ dissipation scale of eddy & [cm] \\
\hline$\lambda$ & $=$ micro scale of turbulence & [cm] \\
\hline$\mu$ & $=$ viscosity of liquid & {$[\mathrm{g} / \mathrm{cm} \cdot \mathrm{sec}]$} \\
\hline$\nu$ & $=$ kinematic viscosity & {$\left[\mathrm{cm}^{2} / \mathrm{sec}\right]$} \\
\hline$\rho_{l}$ & $=$ density of liquid & {$\left[\mathrm{g} / \mathrm{cm}^{3}\right]$} \\
\hline$\rho_{p}$ & $=$ density of solid & {$\left[\mathrm{g} / \mathrm{cm}^{3}\right]$} \\
\hline$\phi_{c}$ & $=$ Carman's surface factor & {$[-]$} \\
\hline
\end{tabular}

\section{Literature Cited}

1) Barker, J. J. and Treybal, R. E.: AIChE J., 6, 289 (1960)

2) Bates, R. L.: Ind. Eng. Chem., Proc. Des. \& Dev., 2, 313 (1963)
3) Brian, P. L. T., H. B. Hales and T. K. Sherwood: AIChE J., 15, 727 (1969)

4) Calderbank, P. H. and M.B. Moo-Young: Chem. Eng. Sci., 16, 39 (1961)

5) "Chem. Engineering Handbook (Japan)", edited by S.C.E.J., p. 926, Maruzen Co. Inc. (1968)

6) Cutter, L. A.: AIChE J., 12, 35 (1966)

7) Harriot, P.: AIChE J., 8, 93 (1962)

8) Harriot, P.: AIChE J., 8, 101 (1962)

9) Helfferich, F.: "Ion Exchange”, p. 255, McGraw Hill Co. Inc. (1962)

10) Hinze, J. O.: “Turbulence", p. 183, McGraw Hill Co. Inc. (1959)

11) Hixson, A. W. and S. J. Baum: Ind. Eng. Chem., 33, 478 (1941)

12) Hughmark, G. A.: Chem. Eng. Sci., 24, 291 (1969)

13) Ishii, T. and S. Fujita: Kagaku Kögaku, 29, 316 (1965)

14) Kawamura, K. and T. Sasano: Kagaku Kögaku, 29, 693 (1965)

15) Levins, D. M. and J. R. Glastonbury: Chem. Eng. Sci., 27, 537 (1972)

16) Middleman, S.: AIChE J., 11, 750 (1965)

17) Nagata, S. and I. Yamaguchi: Kagaku Kogaku, 24618 (1960)

18) Oyama, Y. and K. Endo: Kagaku Kögaku, 20, 576 (1956)

19) Otake, T. and K. Komazawa: Preprints of 37th Annual Meeting of The Soc. of Chem. Engrs., Japan, No. C-107 (1972)

20) Ranz, W. E. and W. R. Marshall: Chem. Eng. Progr., 48, 141 (1952)

21) Sano, Y., T. Adachi and M. Toshimitsu: Preprints of the 7th Autumn Meeting of The Soc. of Chem. Engrs., Japan, No. C-209 (1973)

22) Shinnar, R. and J. M. Church: Ind. Eng. Chem., 52, 253 (1960)

23) Turner, J. C. R., M. R. Church, A.S. W. Johnson and C. B. Snowdon: Chem. Eng.Sci., 21, 317 (1966)

24) Turner, J. C. R. and C. B. Snowdon: Chem. Eng. Sci., 23, 221 (1968) 